\title{
OECD Convergence: A Sectoral Decomposition Exercise
}

\author{
Wei-Kang Wong*
}

May 4, 2006

\begin{abstract}
This paper decomposes OECD convergence into contributions from sectoral productivity growth and contributions from employment shift across sectors. While productivity growth in services and agriculture contributed significantly to convergence, the contributions from employment shift and productivity growth in manufacturing are statistically insignificant.
\end{abstract}

JEL: O41, O47

Keywords: Convergence, Shift-Share Decomposition, $\beta$-Decomposition

${ }^{*}$ Wei-Kang Wong, Assistant Professor, Department of Economics, National University of Singapore, AS2, 1 Arts Link, Singapore 117570, Republic of Singapore. Phone 65-6516-6016, Fax 65-6775-2646, Email ecswong@nus.edu.sg. I especially thank Chad Jones and Till von Wachter for useful comments, and Anders Sørensen for clarification of his methodology. I also thank Julian di Giovanni, Erling Røed Larsen, and Chris Meissner for helpful comments. The usual disclaimer applies. 


\section{Introduction}

Bernard and Jones (1996a, 1996b) find that while labor productivity and multifactor productivity converged in the service sector among OECD countries, they find statistically insignificant convergence in manufacturing. Thus, they conclude that it was the service sector, not manufacturing, that drove aggregate productivity convergence (i.e., convergence in GDP per worker). ${ }^{1}$ There is now quite a large literature on convergence at the sectoral level. ${ }^{2}$

However, the empirical evidence appears to be inconclusive. First, Sørensen (2001) shows that the results on sectoral convergence are sensitive to the choice of base year because sectoral Purchasing-Power-Parities (PPPs) which are needed for international comparison of sectoral productivity levels do not exist. Second, by focusing on convergence within each sector, the existing methodology ignores the effect of structural change on aggregate convergence. ${ }^{3}$ Specifically, even if a less productive sector shows no sign of productivity catch-up, it could still contribute to aggregate convergence by freeing resources for the more productive sectors, allowing the more productive sectors to grow and expand. In fact, the service sector expands while manufacturing contracts in the postwar period in OECD countries. Thus, existing evidence on sectoral convergence may not provide a full account of aggregate productivity convergence.

\footnotetext{
${ }^{1}$ However, applying the same method to U.S. states and industries, Bernard and Jones (1996c) find that it was productivity growth in the manufacturing sector that drove cross-state convergence.

${ }^{2}$ For example, see Gouyette and Perelman (1997), Freeman and Yerger (2001), Pascual and Westermann (2002), and Funk and Strauss (2003).

${ }^{3}$ See Bernard and Jones (1996b), p.1222 and p.1225 for more discussion. Doyle and O'Leary (1999) contend that structural change may be an important factor behind convergence. However, their results are difficult to interpret because they only identify three sectors: manufacturing (which include mining), services (which include construction and utilities), and agriculture.
} 


\section{Methodology and Results}

To address these issues, this paper proposes $\beta$-decomposition to directly decompose aggregate productivity convergence into a component due to sectoral productivity growth, a component due to employment flows across sectors with different productivity relative to aggregate labor productivity, and their interaction. $\beta$-decomposition consists of two steps: The first step decomposes aggregate productivity growth using shift-share decomposition proposed by Maddison (1952):

$$
\triangle y / y=\underbrace{\sum_{j=1}^{k} \underbrace{\left.\frac{Y_{j}\left[\frac{\triangle y_{j}}{Y}\right]}{y_{j}}\right]}_{\text {Weighted Prod. Growth in Sector }}}_{\text {Total Growth Ef fect }}+\underbrace{\sum_{j=1}^{k}\left[\frac{y_{j}}{y}\right] \triangle s_{j}}_{\text {Total Shift Ef fect }}+\underbrace{\sum_{j=1}^{k}\left[\frac{y_{j}}{y}\right]\left(\frac{\triangle y_{j}}{y_{j}}\right)\left(\triangle s_{j}\right)}_{\text {Total Interaction Effect }},
$$

where $\triangle$ denotes change, $y$ is aggregate labor productivity (or GDP per worker), $y_{j}$ is labor productivity of sector $j, Y$ is initial GDP, $Y_{j}$ is initial output of sector $j$, and $s_{j}$ is employment share of sector $j$. The second step regresses the decomposed components from the first step on the logarithm of initial output per worker $\left(\ln y_{0}\right)$ to obtain the following $\beta$-decomposition: ${ }^{4}$

$$
\beta=\sum_{j=1}^{k} \beta_{\text {Productivity Growth in Sector } j}+\beta_{\text {Shift Effect }}+\beta_{\text {Interaction Effect }},
$$

where $\beta$ is "aggregate convergence" - the coefficient estimate obtained from regressing aggregate productivity growth on $\ln y_{0}$, and $\beta_{S}$ denotes the coefficient estimate obtained from regressing the subscripted component $S$ on $\ln y_{0}$. To account for aggregate convergence, the methodology effectively decomposes the $\beta$ coefficient into a sum of component $\beta$ 's.

Equation (2) states that poorer countries may grow faster than the richer ones through three channels: faster sectoral productivity growth, faster employment flows into the more productive

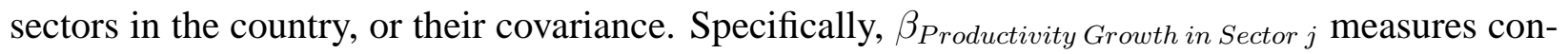

\footnotetext{
${ }^{4} \mathrm{An}$ intercept is also included.
} 
tribution to convergence from productivity growth in sector $j$, which has been weighted by the sector's initial output share in the economy. ${ }^{5}$

The empirical exercise includes seven sectors in 13 OECD countries during 1970-1990. It uses the International Sectoral Database (ISDB), essentially the same sample in Bernard and Jones (1996b). ${ }^{6}$ So that output shares $\left(Y_{j} / Y\right)$ and relative productivity $\left(y_{j} / y\right)$ are not held fixed over extended period of time in the decomposition exercise, I first perform shift-share decomposition for each year and then take the average over the entire sample period. ${ }^{7}$ Table 1 reports the results.

Aggregate convergence is estimated to be 2.46 percentage points, which is statistically significant at the one percent level. Productivity growth in services accounted for 0.59 percentage points or $((0.59 / 2.46) \times 100 \%=) 24$ percent of aggregate convergence. The effect is statistically significant at the ten percent level. Productivity growth in agriculture and construction contributed 0.25 and 0.24 percentage points respectively, amounting to 10 percent of aggregate convergence each. The effects are statistically significant at the one percent level and the five percent level respectively. Productivity growth in manufacturing contributed 0.42 percentage points or 17 percent of aggregate convergence. While this effect is quantitatively large, it is statistically insignificant at the conventional levels. The contributions from productivity growth in mining, non-market, and utilities are relatively small and statistically insignificant. In sum, sectoral productivity growth accounted for 1.78 percentage points or 72 percent of aggregate convergence, which is statistically significant at the one percent level.

\footnotetext{
${ }^{5}$ While it would be interesting to consider total factor productivity, reliable estimates for physical and human capital at the sectoral level are not available.

${ }^{6}$ However, in contrast to Bernard and Jones (1996b), Netherlands is excluded from all regressions because it has missing values in value-added in most service industries in 1970 and the service sector is a key sector under investigation.

${ }^{7}$ An alternative is to use average shares over the period, which should yield similar results.
} 
The contribution to convergence from employment shift turns out to be small. Employment flows across sectors accounted for 0.33 percentage points or only $13 \%$ of aggregate convergence. The interaction effect fails to explain the tendency to converge, contributing only 0.03 percentage points to aggregate convergence. Both effects are statistically insignificant at the ten percent level.

\section{Robustness Checks}

The above calculations use 1990 as the base year. A natural question is whether the results are robust to the choice of base year. To investigate this, I perform two robustness tests.

The first test re-estimates shift-share decomposition and $\beta$-decomposition using 1980 as the base year. The sample period is changed to $1970-85$ because the data come from an earlier version of the ISDB with shorter time series. It turns out that while the magnitudes of the $\beta$ estimates vary, all of the earlier results still hold, except that the contribution to convergence due to productivity growth in the construction sector becomes statistically insignificant at the conventional levels regardless of the base year chosen.

The second test investigates whether the choice of base year affects $\beta$-decomposition through the measurement of initial output per worker (ln $y_{0}$ in the convergence regression). Specifically, Sørensen’s (2001) procedures are used to construct measures of initial output per worker using prices for each base year between 1970 and 1991. The convergence regression is then reestimated. $^{8}$ The findings again turn out to be robust to the choice of base year. ${ }^{9}$

\footnotetext{
${ }^{8}$ Sørensen's procedures are not used to re-estimate shift-share decompositions for different base years because the procedures are based on backward extrapolation using growth rates. In any case, because shift-share decomposition depends on growth rates, ratios, and shares, it should be quite insensitive to problems arising from level comparison.

${ }^{9}$ The details of these two robustness checks are available upon request from the author.
} 


\section{Conclusion}

This paper proposes $\beta$-decomposition to quantify sectoral contributions to OECD convergence. By explicitly incorporating the contributions due to sectoral shift in employment, the methodology provides a complete sectoral account of convergence in GDP per worker. There are a few findings. First, poorer OECD countries grew faster than richer OECD countries because they experienced significantly faster productivity growth in the service sector and the agricultural sector. Second, poorer OECD countries also experienced faster productivity growth in the manufacturing sector. However, while the effect on convergence is quantitatively large, it is not statistically significant at the conventional levels. Third, in sum, sectoral productivity growth contributed significantly to aggregate productivity convergence. Fourth, adjustments in employment structure - the flows of employment into relatively more productive sectors in the economy - are not significantly more rapid in poorer OECD countries. As a result, the contributions to convergence due to employment shift are small and statistically insignificant. Finally, these findings are robust to the choice of base year.

\section{References}

[1] Bernard, A. and C.I. Jones, 1996, Productivity across industries and countries: Time series theory and evidence, Review of Economics and Statistics 78, 135-146.

[2] Bernard, A. and C.I. Jones, 1996, Comparing apples to oranges: Productivity convergence and measurement across industries and countries, American Economic Review 86, 12161238. 
[3] Bernard, A. and C.I. Jones, 1996, Productivity and convergence across U.S. states and industries, Empirical Economics 21, 113-135.

[4] Doyle, E. and E. O'Leary, 1999, The role of structural change in labour productivity convergence among European Union countries: 1970-1990, Journal of Economic Studies 26, 106-120.

[5] Freeman, D.G. and D.B. Yerger, 2001, Interpreting cross-section and time-series tests of convergence: The case of labor productivity in manufacturing, Journal of Economics and Business 53, 593-607.

[6] Funk, M. and J. Strauss, 2003, Panel tests of stochastic convergence: TFP transmission within manufacturing industries, Economics Letters 78, 365-371.

[7] Gouyette, C. and S. Perelman, 1997, Productivity convergence in OECD service industries, Structural Change and Economic Dynamics 8, 279-295.

[8] Maddison, A., 1952, Productivity in an expanding economy, Economic Journal 62, 584-594.

[9] Organization for Economic Cooperation and Development, 1999, International Sectoral Data Base, ISDB 98 (OECD Publications, Paris).

[10] Pascual, A.G. and F. Westermann, 2002, Productivity convergence in European manufacturing, Review of International Economics 10, 313-323.

[11] Sørensen, A., 2001, Comparing apples to oranges: Productivity convergence and measurement across industries and countries: Comment, American Economic Review 91, 1160-1167. 
Table 1: $\beta$-Decomposition of Aggregate Convergence During 1970-90

\begin{tabular}{|c|c|c|c|c|c|}
\hline & Dependent Variable & $\beta$ & Std. Err. of $\hat{\beta}$ & $\mathrm{N}$ & $R^{2}$ \\
\hline 1 & Productivity Growth in Agriculture & $-0.25 * * *$ & 0.08 & 13 & 0.47 \\
\hline 2 & Productivity Growth in Construction & $-0.24 * *$ & 0.08 & 13 & 0.41 \\
\hline 3 & Productivity Growth in Manufacturing & -0.42 & 0.31 & 13 & 0.14 \\
\hline 4 & Productivity Growth in Mining ${ }^{a}$ & -0.17 & 0.21 & 11 & 0.07 \\
\hline 5 & Productivity Growth in Services & $-0.59 *$ & 0.27 & 13 & 0.3 \\
\hline 6 & Productivity Growth in Utilities & 0.01 & 0.09 & 13 & 0 \\
\hline 7 & Productivity Growth in Non-Market Producers & -0.11 & 0.08 & 13 & 0.14 \\
\hline 8 & Total Growth Effect & $-1.78 * * *$ & 0.49 & 13 & 0.54 \\
\hline 9 & Total Shift Effect & -0.33 & 0.21 & 13 & 0.18 \\
\hline 10 & Total Interaction Effect & -0.03 & 0.03 & 13 & 0.11 \\
\hline 11 & Residual Effect ${ }^{b}$ & -0.32 & 0.2 & 13 & 0.18 \\
\hline 12 & Aggregate Labor Productivity & $-2.46 * * *$ & 0.68 & 13 & 0.55 \\
\hline
\end{tabular}

Notes:

Productivity growth in sector $j$ is weighted by its initial output share. The regressors include an intercept and the logarithm of initial output per worker in 1970.

* significant at $10 \%$; ** significant at $5 \%$; ** significant at $1 \%$.

${ }^{a}$ Belgium and Italy are excluded because of missing values.

${ }^{b}$ The residual effect is due to data omission in the ISDB. 